\title{
Integrated Output Filter Inductor for Permanent Magnet Motor Drives
}

\author{
M. Raza Khowja, C. Gerada, G. Vakil, P. Wheeler and C. Patel \\ Power Electronics, Machines and Control (PEMC) Group \\ The University of Nottingham, Nottingham, UK \\ The University of Nottingham, Ningbo, China
}

\begin{abstract}
This paper presents a novel approach to integrate the output filter inductor in permanent magnet synchronous motor (PMSM) drive system. The integrated output filter inductor is based on utilizing the motor magnetics as a filter inductance instead of introducing a separate filter inductor. Thus, eliminating added filter inductor losses and associated weight and volume. The vector controlled model, taking modulation and switching effect in to account, has been developed using MATLAB/Simulink tool for the proposed integrated output filter inductor. The currents obtained from MATLAB/Simulink model are then injected into the Finite Element model to validate the concept. The performance of the proposed and conventional system is analyzed in terms of mean electromagnetic torque, torque ripple, motor losses, inductor losses, weight and volume.
\end{abstract}

Index Terms-- EE Core Inductor, Integrated Inductor, Integration of Passives, Finite Element Analysis (FEA)

\section{NOMENCLATURE}

$K_{f} \quad$ Filter branch factor

$K_{m} \quad$ Motor branch factor $\left(1-K_{f}\right)$

$V_{c} \quad$ Converter voltage

$i_{1} \quad$ Filter branch current

$i_{2} \quad$ Motor branch current

$\omega_{e} \quad$ Electrical input frequency

$\omega_{r} \quad$ Mechanical rotor speed

$T_{e m} \quad$ Electromagnetic torque

$T_{\text {load }} \quad$ Load torque

$J \quad$ Motor inertia

$R_{m} \quad$ Motor winding resistance

$R_{f} \quad$ Damping resistance

$R_{1} \quad$ Filter branch resistance

$R_{2} \quad$ Motor branch resistance

$C_{f} \quad$ Filter capacitance

$L_{m} \quad$ Motor winding inductance

$L_{1}$

$L_{2}$

$X_{L 1}$

$X_{L 2}$

$X_{c}$

$\theta_{e}$

$\psi_{1}$

$\psi_{2}$

$E_{1}$

$E_{2}$

$p$

$\alpha$
II.

\section{INTRODUCTION}

$\mathrm{T}$ HE passive components associated with the drive system such as capacitors, inductors or transformers occupy a significant amount of space and have the added penalties of potential higher weight and loss. Traditionally, filters are designed and introduced after the drive system components have been defined which results in a discrete sub-system for passives. The integrated drives have been a focus of research in power electronics industry. There are different possibilities in drive system to integrate the passive elements. The use of integration in drive system allows functional and structural integration of different drive components into one component that result in a compact design, reduced cost, mass and size reduction, and fewer manufacturing process. Therefore, applications where high power density is needed, an alternative technology for integration have to be looked for [1].

A novel integrated output filter inductor is proposed, which uses the existing motor magnetics as a filter inductance while eliminating the need of a separate filter inductor. The mathematical model of the proposed concept is validated using MATLAB/Simulink. The MATLAB/Simulink simulation results with and without integrated filter are presented and using these simulated results, the operation of the motor with integrated filter is verified through finite element analysis (FEA).

\section{LITERATURE REVIEW}

\section{A. Integrated Filter Inductor Designs}

In recent times, the passive integration has been focused in power electronics and drive applications that have resulted in an overall compact and power dense system. In [1-4], the perspective on the integrated filter inductors are presented that motivates the drive integration on a system level. The design of integrated filter inductor for power factor correction application is presented in [1]. The paper modified the stator laminations to increase the stator back iron, which act as an integrated filter inductor. This modification increases the outer diameter of the motor.

The stator back iron is used as a magnetic component by integrating toroidal winding which drives alternating magnetic flux in the complete loops through the back iron of the stator core. If the stator back iron of the machine is operating in linear region then the presence of ring flux due to inductor winding will not affect the main machine flux [2-3]. 
The principle of electromagnetic integration is used for integrating capacitor in the same magnetic component as that of the inductor. "The integrated filter is the planar integrated L-C winding, which consists of a dielectric substrate with conductor windings directly deposited on both sides. Thus, resulting in a distributed inductance and capacitance structure. Moreover, different equivalent circuits have been achieved by connecting the terminals of integrated LC structure in an appropriate manner" [4-9].

The same principle of [4-9] is applied for C-core EMI inductor in [11-12]. "The distributed capacitance is implemented in the conventional way, whereas the inductor is implemented by utilizing the cathode and anode foils of the capacitor to form the windings. The windings are then enclosed in a can, which has a hole in the middle for the magnetic core".

\section{NOVEL INTEGRATED OUTPUT FILTER INDUCTOR}

The motor with integrated output filter inductor is based on utilizing the motor winding inductance as a filter inductance, instead of introducing a separate filter inductor. Fig. 1(a) and Fig. 1(b) show both conventional and integrated drive system respectively.

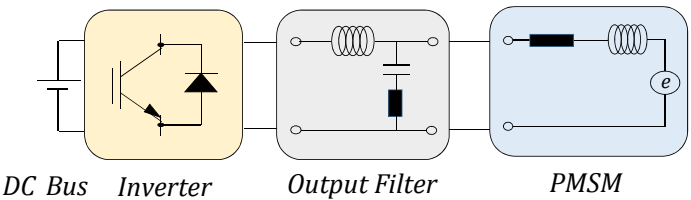

(a) Conventional PMSM Drive

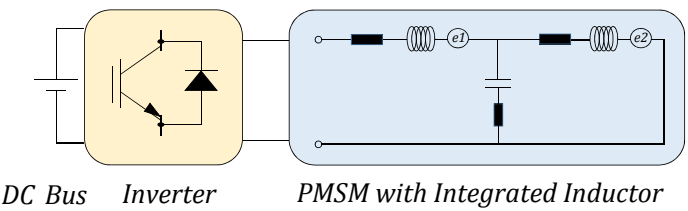

(b) Integrated PMSM Drive System

Fig. 1: Conventional and integrated PMSM drive system

It can be seen that the proposed motor with integrated inductor does not include a separate inductor, thus eliminating added filter inductor losses and associated weight and size. Filter capacitor and damping resistor are placed between the motor windings to form an integrated RLC output filter using inductance of motor winding.

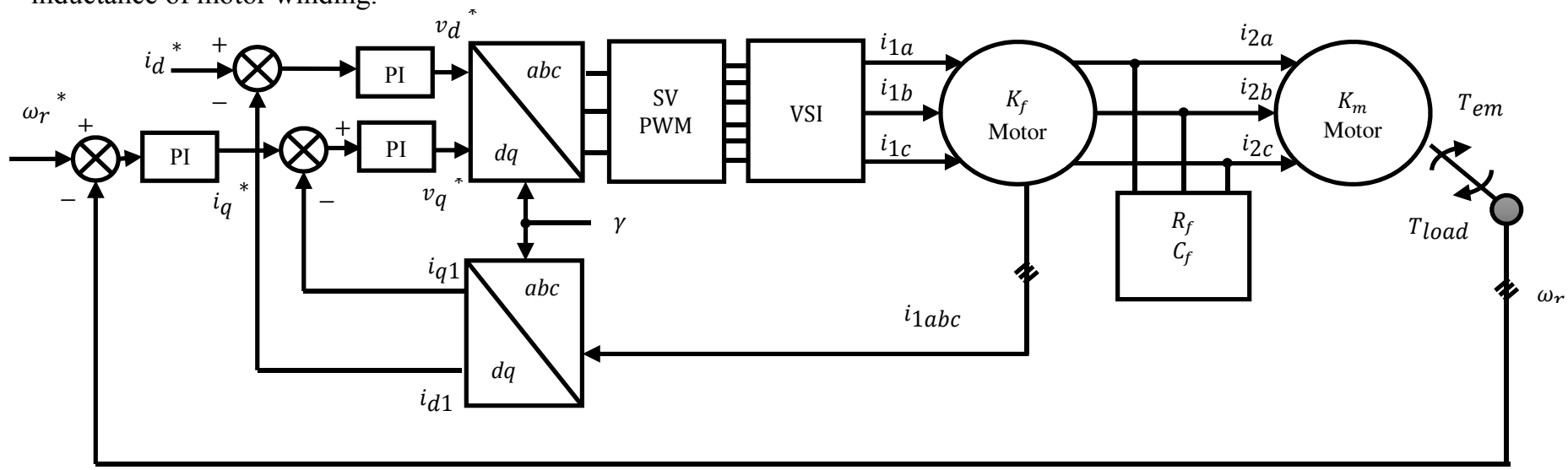

Fig. 2: Control block diagram of the proposed motor with integrated inductor
The value of the inductance can be varied by - varying proportion of motor winding used as filter and varying the capacitance of the integrated RLC filter for the same cut-off frequency. The motor is divided into two branches; filter branch and the motor branch. The motor branch windings will see the filtered sinusoidal currents, whereas PWM switching currents will flow through the filter branch winding, which is the fraction of the motor winding.

\section{A. $\quad$ Vector Control Modelling}

A detailed vector control model of the proposed motor with integrated inductor, taking switching effect and modulation into account, has been developed using MATLAB/Simulink tool. The control system block diagram of the motor with integrated inductor is shown in Fig. 2. 12 slots, 10 poles surface mounted permanent magnet motor is considered. The motor drive specifications are shown in Table I. The motor is operating at a speed of 2100rpm and load torque of $1.5 \mathrm{Nm}$ with corresponding peak current of $5.85 \mathrm{~A}$. The cross sectional view of the motor with integrated inductor

TABLE I: MOTOR-DRIVE SPECIFICATIONS AND OPERATING CONDITIONS

\begin{tabular}{|c|c|c|}
\hline PARAMETERS & VALUES & UNITS \\
\hline DC Bus Voltage & 200 & $\mathrm{~V}$ \\
\hline Fundamental Frequency & 0.175 & \multirow{2}{*}{$\mathrm{kHz}$} \\
\hline Switching Frequency & 10 & - \\
\hline No. of Turns per phase & $2 \times 46$ & $\mathrm{Nm}$ \\
\hline Operating Torque & 1.5 & $\mathrm{RPM}$ \\
\hline Operating Speed & 2100 & $\Omega$ \\
\hline Phase Resistance & $2 \times 0.21$ & $\mathrm{mH}$ \\
\hline Phase Inductance & $2 \times 1.29$ & $\mathrm{~A}$ \\
\hline Peak Current & 5.85 & \\
\hline
\end{tabular}

The mathematical model is based on abc reference frame and corresponding abc currents are transformed into $\mathrm{d}-\mathrm{q}$ reference frame for controlling purpose. The filter branch currents are controlled to produce maximum torque of the filter branch. The filter capacitor and damping resistor are connected in between filter and motor branch. It should be noted that, inserting filter capacitance and resistance between the motor winding will introduce a phase shift between two branch currents, i.e. $i_{1 a b c}$ and $i_{2 a b c}$. is shown in Fig. 3. 
The mathematical equations needed to model the proposed motor with integrated inductor can be obtained by using per phase equivalent circuit. The per-phase equivalent circuit of the motor with integrated inductor is shown in Fig. 4(a).

By applying KVL on filter branch we have,

$V_{1 a}(t)=R_{1} i_{1 a}+L_{1} \frac{d}{d t} i_{1 a}+\frac{d}{d t} \psi_{1} \cos \theta_{e}+\frac{1}{C_{f}} \int\left(i_{1 a}-i_{2 a}\right) d t+$

$R_{f}\left(i_{1 a}-i_{2 a}\right)$

Converting Eq. 1 into s-domain by taking Laplace transformation on both sides we have,

$V_{1 a}(s)=R_{1} i_{1 a}+L_{1} i_{1 a} s-\omega_{e} \psi_{1} \sin \theta_{e}+\frac{1}{C_{f} s}\left(i_{1 a}-i_{2 a}\right)+$

$R_{f}\left(i_{1 a}-i_{2 a}\right)$

Solving for $i_{1 a}=\frac{1}{s L_{1}}\left(V_{c a}+\omega_{e} \psi_{1} \sin \theta_{e}-R_{1} i_{1 a}-R_{f} i_{1 a}+\right.$ $\left.R_{f} i_{2 a}-\frac{1}{s C_{f}} i_{1 a}+\frac{1}{s C_{f}} i_{2 a}\right)$

The current of phase $\mathrm{b}$ and $\mathrm{c}$ with $120^{\circ}$ phase shifts are,

$$
\begin{gathered}
i_{1 b}=\frac{1}{s L_{1}}\left(V_{c b}+\omega_{e} \psi_{1} \sin \left(\theta_{e}+\frac{2 \pi}{3}\right)-R_{1} i_{1 b}-R_{f} i_{1 b}\right. \\
\left.+R_{f} i_{2 b}-\frac{1}{s C_{f}} i_{1 b}+\frac{1}{s C_{f}} i_{2 b}\right) \\
i_{1 c}=\frac{1}{s L_{1}}\left(V_{c c}+\omega_{e} \psi_{1} \sin \left(\theta_{e}+\frac{2 \pi}{3}\right)-R_{1} i_{1 c}-R_{f} i_{1 c}\right. \\
\left.+R_{f} i_{2 c}-\frac{1}{s C_{f}} i_{1 c}+\frac{1}{s C_{f}} i_{2 c}\right)
\end{gathered}
$$

Similarly for the motor branch we have,

$0=R_{2} i_{2 a}+L_{2} \frac{d}{d t} i_{2 a}+\frac{d}{d t} \psi_{2} \cos \theta_{e}+\frac{1}{C_{f}} \int\left(i_{2 a}-i_{1 a}\right) d t+$

$R_{f}\left(i_{2 a}-i_{1 a}\right)$

Converting Eq. 6 into s-domain by taking Laplace transformation on both sides we have,

$$
\begin{aligned}
0= & R_{2} i_{2 a}+L_{2} i_{2 a} s-\omega_{e} \psi_{2} \sin \theta_{e}+\frac{1}{C_{f} s}\left(i_{2 a}-i_{1 a}\right)+ \\
& R_{f}\left(i_{2 a}-i_{1 a}\right)
\end{aligned}
$$

Solving for $i_{2 a}=\frac{1}{s L_{2}}\left(0+\omega_{e} \psi_{2} \sin \theta_{e}-R_{2} i_{2 a}-R_{f} i_{2 a}+\right.$

$\left.R_{f} i_{1 a}-\frac{1}{s C_{f}} i_{2 a}+\frac{1}{s C_{f}} i_{1 a}\right)$

The current of phase $\mathrm{b}$ and $\mathrm{c}$ with $120^{\circ}$ phase shifts are,

$$
\begin{gathered}
i_{2 b}=\frac{1}{s L_{2}}\left(0+\omega_{e} \psi_{2} \sin \left(\theta_{e}+\frac{2 \pi}{3}\right)-R_{2} i_{2 b}-R_{f} i_{2 b}+R_{f} i_{1 b}\right. \\
\left.-\frac{1}{s C_{f}} i_{2 b}+\frac{1}{s C_{f}} i_{1 b}\right)
\end{gathered}
$$

$$
\begin{gathered}
i_{2 c}=\frac{1}{s L_{2}}\left(0+\omega_{e} \psi_{2} \sin \left(\theta_{e}+\frac{2 \pi}{3}\right)-R_{2} i_{2 c}-R_{f} i_{2 c}+R_{f} i_{1 c}\right. \\
\left.-\frac{1}{s C_{f}} i_{2 c}+\frac{1}{s C_{f}} i_{1 c}\right)
\end{gathered}
$$

\section{B. Split Winding Configuration}

The split winding configuration uses a part of motor winding as a filter inductance. This filter inductance forms a part of integrated RLC filter that attenuates the switching frequency component for a defined cut-off frequency. Fig. 3 shows the practical implementation of the split winding configuration.

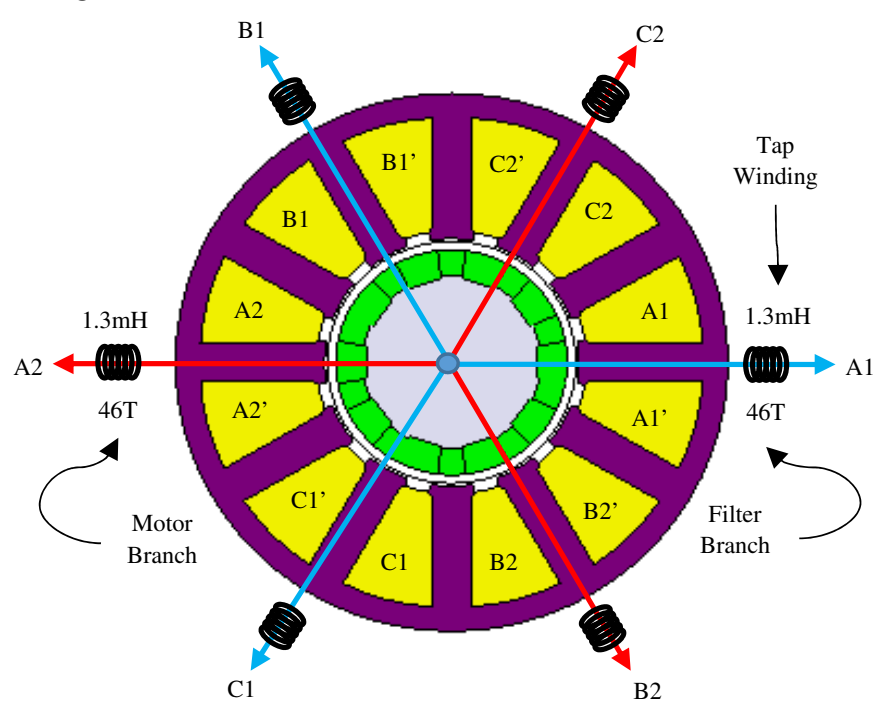

Fig. 3: Winding formulation of 12 Slots 10 Poles integrated permanent magnet synchronous motor

Initially, the motor has a total inductance of $2.6 \mathrm{mH}$ and 92 turns per phase. The required inductance of $1.3 \mathrm{mH}$ is considered for filter branch leaving $1.3 \mathrm{mH}$ for the motor branch. In Fig. 3, the vectors A1, B1 and C1represent the filter branch, whereas the vectors $\mathrm{A} 2, \mathrm{~B} 2$ and $\mathrm{C} 2$ correspond to the motor branch. The filter branch can be tapped based on the required filter inductance. In such a case, the number of turns in the filter branch winding will reduce through the tapings as per required inductance and the remaining turns would be added to the motor branch.

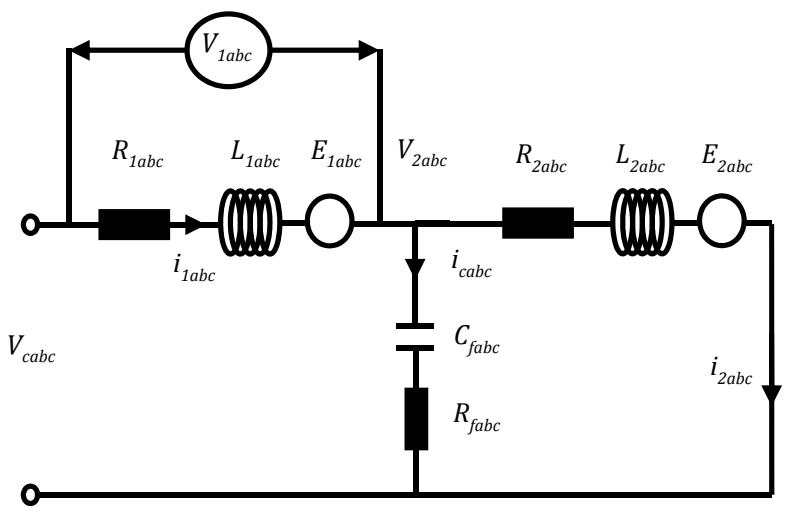

a) per-phase equivalent circuit 


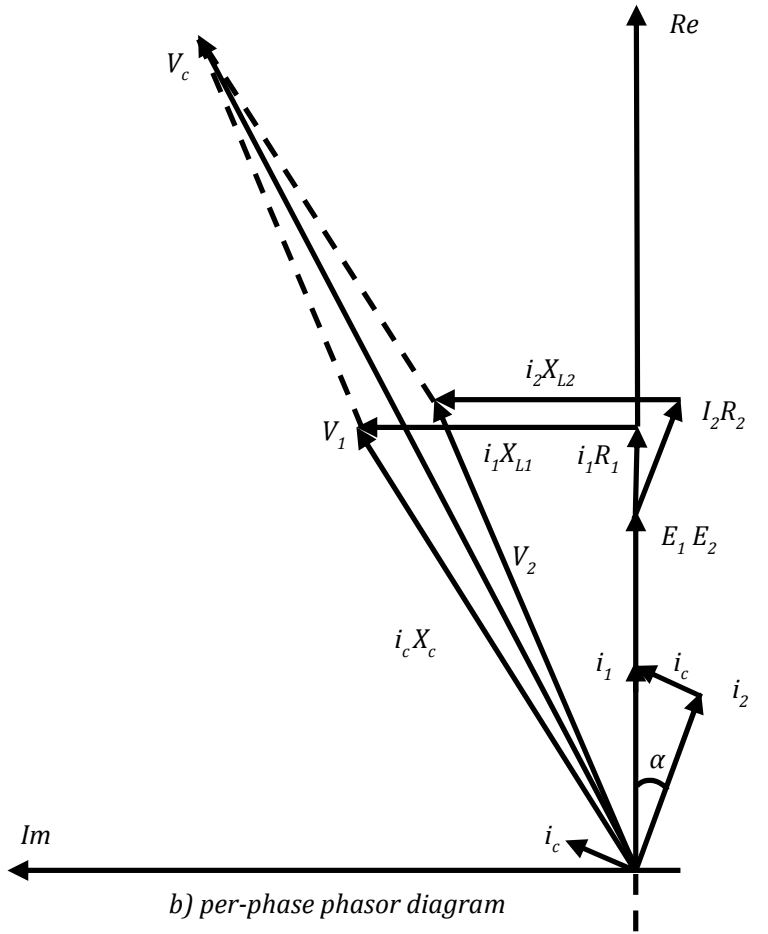

Fig. 4: Per-phase equivalent circuit and phasor diagram of integrated permanent magnet synchronous motor

\section{Per Phase Phasor Representation}

The per-phase equivalent circuit and the phasor diagram of the proposed motor with integrated inductor are shown in Fig. 4(a) and Fig. 4(b) respectively. For steady state analysis, the voltage equations are:

$$
\begin{gathered}
\overline{V_{1}}=\overline{i_{1}} R_{1}+\overline{i_{1}} X_{L 1}+\overline{E_{1}} \\
\overline{V_{2}}=\overline{i_{2}} R_{2}+\overline{i_{2}} X_{L 2}+\overline{E_{2}}=\overline{i_{c}} R_{f}+\overline{i_{c}} X_{C}
\end{gathered}
$$

The converter voltage is given by,

$$
\overline{V_{c}}=\overline{V_{1}}+\overline{V_{2}}
$$

$E_{1}$ and $E_{2}$ are taken as reference vector. Since $i_{1}$ is controlled, $i_{1} * R_{1}$ voltage drop is in phase with $E_{1}$ while reactive voltage drop is at $90^{\circ}$ with respect to $i_{1}$ and the converter voltage $V_{c}$ is the resultant phasor of all voltages in the filter branch. Since $i_{2}$ is left uncontrolled, $i_{1}$ is leading by $i_{2}$ due to the addition of filter capacitor. The active and reactive drop for the motor branch is in phase and orthogonal with respect to $i_{2}$ respectively and the voltage $V_{2}$ is the resultant phasor of all voltage drops in the motor branch. Capacitor current $i_{c}$ is leading $V_{2}$ by less than $90^{\circ}$ due to damping resistor. The phasor summation of $i_{c}$ and $i_{2}$ will make the total branch current $i_{1}$. Filter branch currents $i_{1}$ is phase shifted (leading) by motor branch current $i_{2}$ by an angle $\alpha$. The phase shift angle $\alpha$ between two currents can be calculated as,

$$
\alpha=\cos ^{-1}\left(\frac{i_{1}^{2}+i_{2}^{2}-i_{c}^{2}}{2 i_{1} i_{2}}\right)
$$

\section{$D$.} Electromagnetic Torque

The electromagnetic torque developed by the surface mounted permanent magnet synchronous motor is given by,

$$
T_{e m}=K \psi_{m} i_{a}
$$

From the equivalent circuit of proposed model, shown in Fig. 4(a), Eq. 15 is not valid to calculate the electromagnetic torque developed by the motor with integrated inductor. There are now two torque components developed by the motor with integrated filter,

1. Torque due to the filter branch winding, $T_{a 1}$ and,

2. Torque due to the motor branch winding, $T_{a 2}$

Therefore, the electromagnetic torque developed by the motor with integrated filter is,

$$
\begin{gathered}
T_{e m}=T_{a 1}+T_{a 2} \\
T_{e m}=3 \frac{p}{2}\left(\psi_{1} i_{1}+\psi_{2} i_{2} \cos \alpha\right)
\end{gathered}
$$

This electromagnetic torque will cause the speed response which is defined by,

$$
\omega_{r}=\frac{1}{J s}\left(T_{e m}-T_{l o a d}\right)
$$

\section{E. MATLAB/Simulink and FEA Results}

RLC output filter was designed [13] with cut-off frequency $2 \mathrm{kHz}$ and maximum frequency (to avoid the resonance between filter capacitance and motor inductance) $1.2 \mathrm{kHz}$. The corresponding RLC values for the filter were selected as $2 \Omega$, $1.29 \mathrm{mH}$ and $4.9 \mu \mathrm{F}$ respectively. Subsequently, the filter branch winding was fixed to $1.29 \mathrm{mH}$ leaving rest of the windings as motor branch.

Fig. 5(a) and Fig. 5(b) show the line voltage across the inverter terminal and the line voltage across the motor branch winding respectively. The current through the filter branch and motor branch are shown in Fig. 5(c) and Fig. 5(d) respectively. The filter branch currents have been injected in to the FEA model of the motor with integrated inductor to validate the effect of the integrated filter. The currents of the motor branch seen from the FEA model were identical to that of MATLAB/Simulink model and are shown in Fig. 5(d). The result shows that the half of the motor winding sees the filtered voltages. Thus, reduces the voltage stress and PWM losses in half of the motor winding. Moreover, the added losses, weight and size due to external filter inductor will also be eliminated.

It is important to note that the voltage with high gradient is dropped across the filter branch winding. The insulation of the filter branch can be made high to bear the PWM voltage stress. This will allow the integrated filter feasible for the applications where long cables are used between inverter and motor terminal.

The MATLAB/Simulink results of the motor without filter and with conventional filter are shown in Fig. 6 and Fig. 7 
respectively. It can be seen from Fig. 5(c) and Fig. 7(c) that the filtering effect of the motor with integrated inductor and conventional RLC filter are alike.

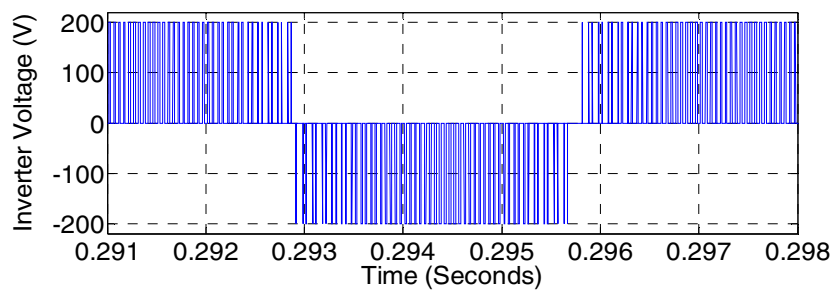

(a) MATLAB Inverter Terminal Voltage with Integrated Filter

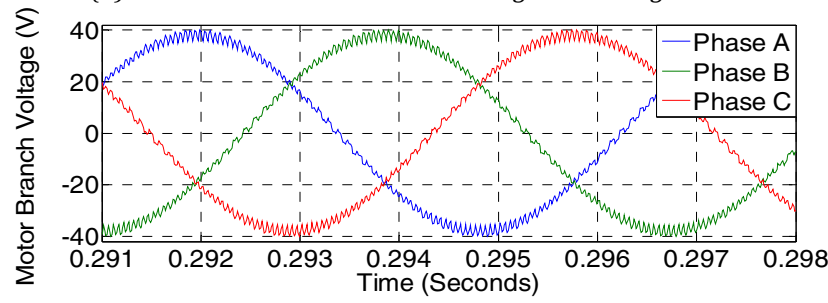

(b) MATLAB Motor Branch Voltage with Integrated Filter

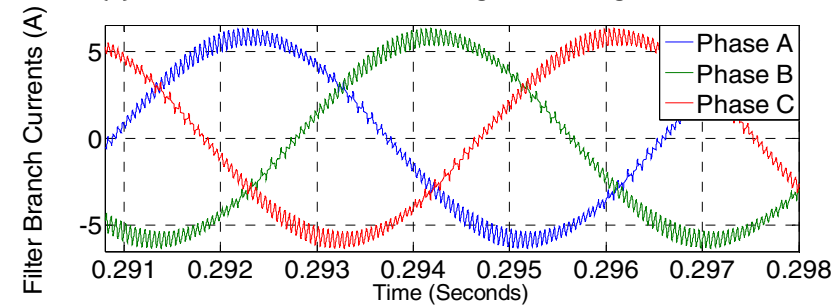

(c) MATLAB Filter Branch Currents with Integrated Filter

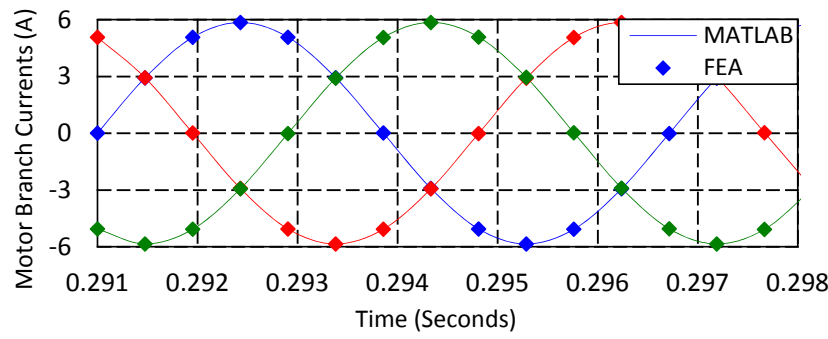

(d) MATLAB and FEA Motor Branch Currents with Integrated Filter

Fig. 5: MATLAB/Simulink results of the Motor with integrated inductor

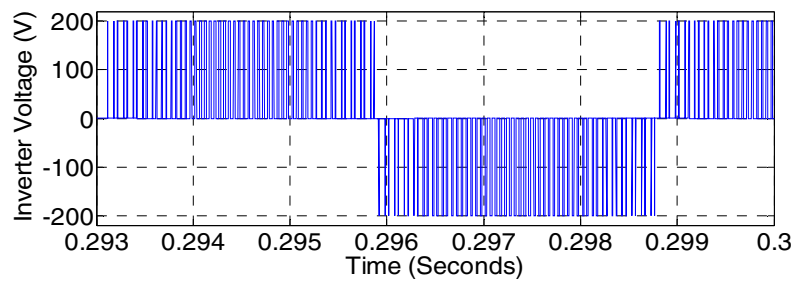

(a) MATLAB Inverter Terminal Voltage without Filter

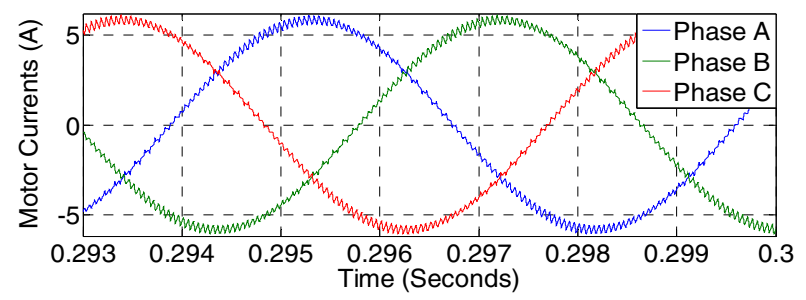

(b) MATLAB Motor Currents without Filter

Fig.6: MATLAB/Simulink results of the motor without filter

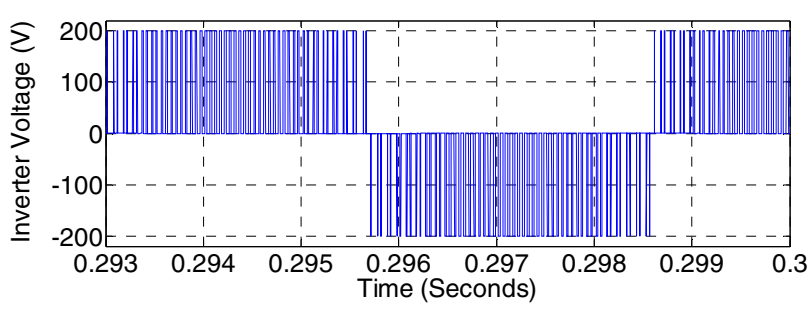

(a) MATLAB Inverter Terminal Voltage with External Inductor

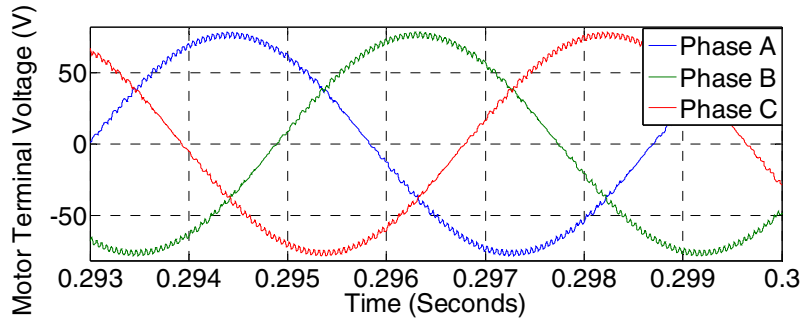

(b) MATLAB Motor Terminal Voltage with External Inductor

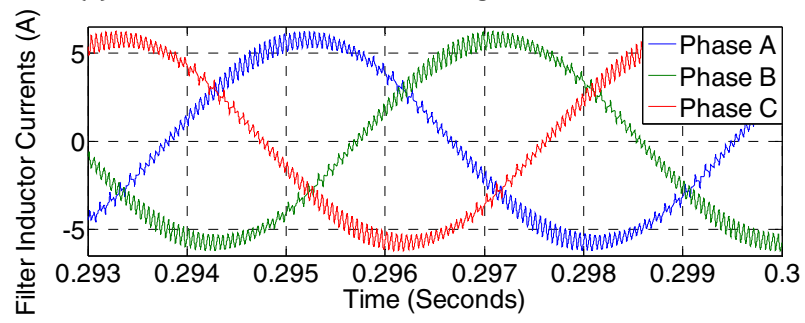

(c) MATLAB Filter Inductor Currents with External Inductor

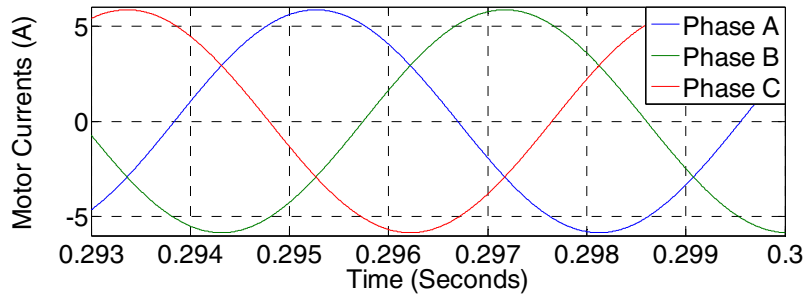

(d) MATLAB Motor Currents with External Inductor

Fig. 7: MATLAB/Simulink results of the motor with external inductor

To get utmost benefit out of the proposed motor with integrated inductor, the filter branch has to be quarter or less of the entire motor winding so that a higher portion of the motor winding experiences the filtered currents. This will depend on the design of the output filter i.e. inductance and capacitance required to attenuate the switching component of the inverter. However, the reduction in filter inductance will increase the capacitance for the same cut-off frequency by the given relation,

$$
\omega_{\text {cut-off }}=\sqrt{\frac{1}{L_{1} C_{f}}}
$$

\section{F. FEA Based Motor Performance}

The motor performance depicted in Tables II and III of the proposed and conventional filter has been compared in terms of mean electromagnetic torque, torque ripple, total losses, inductor weight and volume. The external filter inductor is designed [14] and validated with FEA. The cross sectional view of external filter inductor is shown in Fig. 8 and the specifications are shown in Table IV. It is evident that the losses, weight and volume have been reduced in the motor with integrated inductor. It is also worth noting that the effect 
on the mean electromagnetic torque due to angle $\alpha$ is negligible. However, torque ripple become relatively higher when compared to the motor with external filter inductor due to the presence of switching current component in the filter branch. This can be observed from Fig. 9 which shows the electromagnetic torque with and without filter.

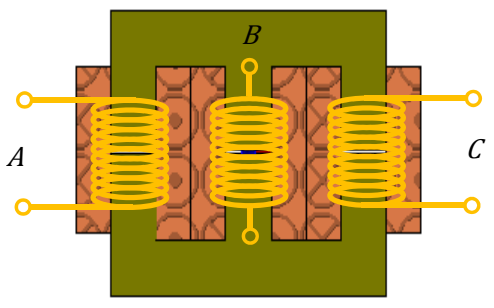

Fig. 8: Cross sectional view of external filter inductor

TABLE II: FEA BASED MOTOR LOSSES OF BOTH SySTEMS

\begin{tabular}{|c|c|c|c|c|c|}
\hline $\begin{array}{c}\text { MOTOR } \\
\text { WITH }\end{array}$ & $\begin{array}{c}\text { Motor } \\
\text { Losses } \\
(\mathrm{W})\end{array}$ & $\begin{array}{c}\text { External } \\
\text { Inductor } \\
\text { Losses } \\
(\mathrm{W})\end{array}$ & $\begin{array}{c}\text { Total } \\
\text { Losses } \\
(\mathrm{W})\end{array}$ & $\begin{array}{c}\text { External } \\
\text { Inductor } \\
\text { Weight } \\
(\mathrm{Kg})\end{array}$ & $\begin{array}{c}\text { External } \\
\text { Inductor } \\
\text { Volume } \\
\left(\mathrm{cm}^{3}\right)\end{array}$ \\
\hline $\begin{array}{c}\text { Integrated } \\
\text { Inductor }\end{array}$ & 36 & 0 & 36 & 0 & 0 \\
\hline $\begin{array}{c}\text { External } \\
\text { Inductor }\end{array}$ & 26.1 & 40.67 & 66.77 & 1.52 & 338.7 \\
\hline
\end{tabular}

TABLE III: FEA BASED MOTOR TORQUE RIPPLE OF BOTH SYSTEMS

\begin{tabular}{|c|c|c|c|c|}
\hline $\begin{array}{c}\text { MOTOR } \\
\text { WITH }\end{array}$ & $\begin{array}{c}\text { Mean } \\
\text { Torque } \\
(\mathrm{Nm})\end{array}$ & $\begin{array}{c}\text { Torque Ripple } \\
(\%) \text { at } \mathrm{T}_{\text {load }}= \\
1.5 \mathrm{Nm}\end{array}$ & $\begin{array}{c}\text { Torque Ripple } \\
(\%) \text { at } \mathrm{T}_{\text {load }}= \\
3 \mathrm{Nm}\end{array}$ & $\begin{array}{c}\text { Torque Ripple } \\
(\%) \text { at } \mathrm{T}_{\text {load }}= \\
4.5 \mathrm{Nm}\end{array}$ \\
\hline $\begin{array}{l}\text { Integrated } \\
\text { Inductor }\end{array}$ & 1.485 & 9.54 & 5.33 & 4.2 \\
\hline $\begin{array}{l}\text { External } \\
\text { Inductor }\end{array}$ & 1.49 & 0.7 & 0.574 & 0.54 \\
\hline
\end{tabular}

TABLE IV: INDUCTOR DESIGN SPECIFICATIONS

\begin{tabular}{|c|c|c|}
\hline PARAMETERS & VALUES & UNIT \\
\hline Material & $\mathrm{M}-1529 \mathrm{Ga}$ & - \\
\hline Required Inductance & 1.3 & $\mathrm{mH}$ \\
\hline Peak Current & 18 & $\mathrm{~A}$ \\
\hline Turns per phase & 20 & - \\
\hline Fill Factor & 0.49 & - \\
\hline Conductor Diameter & 2.62 & $\mathrm{~mm}$ \\
\hline Peak Current Density & 3.3 & $\mathrm{~A} / \mathrm{mm}^{2}$ \\
\hline
\end{tabular}

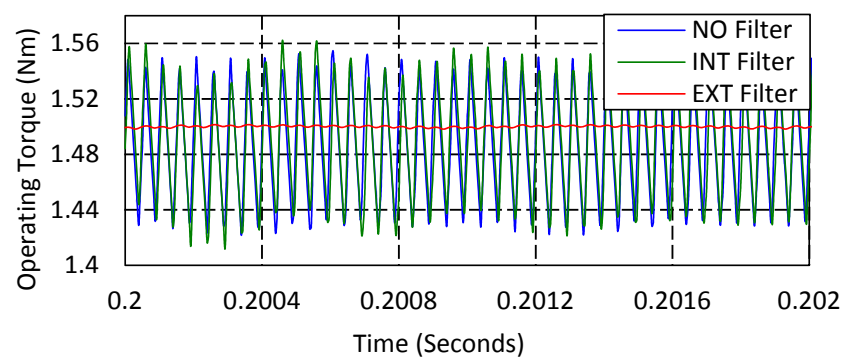

Fig. 9: FEA torque ripple comparison with and without filter

\section{CONCLUSIONS}

An integrated filter inductor for permanent magnet motor drive is proposed in this paper. The proposed motor with integrated inductor eliminates the need of a separate filter inductor which reduces the overall losses, and associated weight and volume. From MATLAB/Simulink results, it has been observed that the voltage stress and losses due to PWM are eliminated in the motor branch. The inductor losses, weight and volume related with the separate inductor are $40.67 \mathrm{~W}, 1.52 \mathrm{Kg}$ and $338.7 \mathrm{~cm}^{3}$ whereas these losses, weight and volume are removed in the motor with integrated inductor. However, the torque ripple was relatively higher when compared to the motor with external inductor. This is due to the presence of switching component in the filter branch. The MATLAB/Simulink and FEA results show that this integrated approach is feasible and can be practically implemented. The proposed concept can be a suitable solution for high power $\mathrm{AC}$ drives where bulky and lossy inductors are required but this comes at the expense of relatively higher torque ripple.

\section{REFERENCES}

[1] Nee B.M, Chapman P.L. "Integrated Filter Element in Electric Drives" Vehicle Power and Propulsion Conference, 2007. VPPC 2007. IEEE. Publication Year: 2007, Page(s): 148 - 153

[2] Garvey S.D. Norris, W.T, Wright M.T. "The role of integrated components in protecting motor windings". Electric Power Applications, IEEE Proceedings - Volume: 147, Issue: 5 Publication Year: 2000

[3] Nakajima, Yuki Imazu, Tomoya Mizukoshi, Yukio Sato, Sho Zushi, Yusuke "Integrated Capacitor Type Stator", Patent No. 8049383

[4] Chen R, van Wyk J.D, Wang S, Odendaal W.G. "Planar electromagnetic integration technologies for integrated EMI filters". Industry Applications Conference, 2003. 38th IAS Annual Meeting. Conference Record of the Volume: 3. Publication Year: 2003

[5] Fang Luo, Robutel R, Shuo Wang, Wang F, Boroyevich D. "Integrated Input EMI Filter for a $2 \mathrm{~kW}$ DC-fed 3-phase Motor Drive". Applied Power Electronics Conference and Exposition, 2009. APEC 2009. Twenty-Fourth Annual IEEE. Publication Year: 2009, Page(s): 325 - 329

[6] Chen R, Shuo Wang, van Wyk J.D, Odendaal W.G. "Integration of EMI filter for distributed power system (DPS) front-end converter" Power Electronics Specialist Conference, 2003. PESC '03. 2003 IEEE 34th Annual Volume: 1 Publication Year: 2003, Page(s): 296 - 300 [7] Zhao L, Strydom J.T, van Wyk J.D. "Wide band modelling of integrated passive structure: the series resonator". Power Electronics Specialists Conference, 2002. pesc 02. 2002 IEEE 33rd Annual Volume:3. Publication Year: 2002, Page(s): 1283 - 1288 vol.3

[8] Lingyin Zhao Strydom J.T, van Wyk J.D. "An alternative planar multicell structure integrated reactive module" Industry Applications Conference, 2001. Thirty-Sixth IAS Annual Meeting. Conference Record of the 2001 IEEE Volume: 4 Publication Year: 2001, Page(s): 2217 - 2223 vol.4

[9] Chen R, Strydom J.T, van Wyk J.D. "Design of planar integrated passive module for zero-voltage switched asymmetrical half bridge PWM converter" Industry Applications, IEEE Transactions on Volume: 39, Publication Year: 2003, Page(s): 1648 - 1655

[10] Strydom J.T, van Wyk J.D, Ferreira J.A. "Some limits of integrated LCT modules for resonant converters at $1 \mathrm{MHz}$ " Industry Applications Conference, 1999. Thirty-Fourth IAS Annual Meeting. Conference Record of the 1999 IEEE. Publication Year: 1999, Page(s): 1411 - 1417 vol.2

[11] Popovic-Gerber Jelena, Gerber M, Ferreira Braham "Integrated filter in electrolytic capacitor technology for implementation in high power density idustrial drives" Power Electronics Specialists Conference, 2008. PESC 2008. IEEE. Publication Year: 2008, Page(s): 2968 - 2974

[12] Popovic J, Ferreira J.A, Gerber M.B, Konig A, de Doncker, R. "Integration technologies for high power density power electronic converters for AC drives". Power Electronics, Electrical Drives, Automation and Motion, 2006. SPEEDAM 2006. Publication Year: 2006 , Page(s): 634 - 639

[13] Sozer Y, Torrey D.A, Reva S. "New inverter output filter topology for PWM motor drives" Applied Power Electronics Conference and Exposition, 2000. APEC 2000. Fifteenth Annual IEEE Volume: 2. Publication Year: 2000 , Page(s): $911-917$ vol.2

[14] Kazimierczuk M.K, Sekiya H. "Design of AC resonant inductors using area product method" Energy Conversion Congress and Exposition, 2009. ECCE 2009. IEEE Publication Year: 2009 